\title{
"Como posso ter saudades de um tempo que não vivi?" Reflexões acerca da força evocativa de uma memória ferroviária na cidade de Santa Maria - RS
}

"How can I miss a time not lived?" Reflections on the evocative power of a railway memory in the town of Santa Maria-RS

"¿Cómo puedo tener nostalgia de un tiempo que no viví?" Reflexiones acerca de la fuerza evocativa de la memoria ferrocarril en la ciudad de Santa Maria - RS

Maria Catarina Zanini

\section{Resumo}

Este artigo tem por objetivo refletir acerca do processo de construção de narrativas memorialistas relacionadas ao mundo ferroviário na cidade de Santa Maria, situada na região central do estado do Rio Grande do Sul (Brasil). Por meio de pesquisa documental e etnográfica, faz-se, neste artigo, a análise de narrativas em que a ferrovia e suas dinâmicas aparecem como motores de expressão. O que se observa é que a força evocativa da presença e da história da ferrovia tornaram-se uma marca da cidade e de sua trajetória.

Palavras-chave: Memórias. Ferrovia. Santa Maria.
Este artigo tem por objetivo refletir acerca do processo de construção de narrativas memorialistas relacionadas ao mundo ferroviário na cidade de Santa Maria, situada na região Central do estado do Rio Grande do Sul (Brasil). A cidade teve sua existência cruzada com os destinos da ferrovia, tornando-se importante centro ferroviário. Seu crescimento e urbanização processaram-se juntamente com a formação da rede férrea local (BELTRÃO, 1979) e sua expansão. A

\footnotetext{
Doutora em Ciência Social (Antropologia Social) pela Universidade de São Paulo. Professora Associada I, Universidade Federal de Santa Maria. Professora Programa de Pós-Graduação em Ciências Sociais UFSM.
}

Recebido em: 28/08/2012 - Aprovado em: 10/12/2012 http://dx.doi.org/10.5335/hdtv.13n.2.3721 
ferrovia trouxe para o cenário da cidade e região novas relações de trabalho e também de prestígio e distinção sociais. Houve o crescimento de uma elite trabalhadora vinculada a esta, que possuía benefícios e ganhos que outros trabalhadores na cidade não tinham, o que lhes garantia certa distinção compartilhada e um orgulho de pertencer a essa "classe". Além disso, a ferrovia alterou a paisagem local e as noções de tempo e espaço existentes, permitindo novos trânsitos entre bens materiais, simbólicos e de relações sociais. Ela representou, no cenário brasileiro, como salienta Foot Hardman (1988) a interiorização do estado nacional e do capitalismo e, ao mesmo tempo, representava modernidade e progresso.

Por meio de pesquisa documental e etnográfica ${ }^{1}$, faz-se a análise de narrativas em que a ferrovia e suas dinâmicas aparecem como motores de expressão. Tais narrativas foram por nós coletadas em fontes diversas: jornais, livros, entrevistas e outras documentações. Todas serão analisadas partindo de suas vinculações com as construções memorialistas, independente do formato ou do gênero de sua textualidade (se poema, crônica, entrevista, reportagem, entre outras fontes). Por memória entende-se, segundo Halbwachs (1990), a construção sobre o passado que é elaborada no presente, com suas estruturas de sentido e significação contemporâneas. As construções memorialistas são, dessa forma, observadas como leituras possíveis acerca do passado e não necessariamente o dito de um passado que possa ser verificado e questionado por meio de fontes, datações ou comprovações do vivido. Trata-se de possibilidades interpretativas mediadas pe- las capacidades e interesses narrativos dos sujeitos memorialistas. São elementos vividos e ouvidos em diálogo, numa constante formação discursiva sobre o mundo ferroviário na cidade.

Gostaria de iniciar este artigo refletindo a respeito do título, dito de uma jovem mulher acerca dos trens, trilhos e suas passagens. Ela refere-se a ter saudades de um tempo que não viveu, mas do qual partilha sentidos, sentimentos e paisagens. Sentimento que é possibilitado por meio das memórias que circulam em seu coletivo e de suas atualizações. Vivendo tais acontecimentos de fato ou "por tabela" (POLLAK, 1989, 1992), o que importa é o peso de tal construção de referência identitária e de sentido. Este artigo não traz somente a fala de ferroviários e seus descendentes, mas também de pessoas comuns para quem a ferrovia representou e ainda representa muito enquanto construto simbólico e de referência de mundo. A ferrovia de que falamos aqui é um lugar antropológico (AUGÉ, 1994, p. 51), repleto de sentidos e inteligibilidades sociais. Transitando entre o glamour, a modernização e o sentimento de sucateamento que acompanha a situação desta hoje, esse lugar, marca e marcação de destinos é produto e produtor de inúmeras versões acerca de si mesmo e também da cidade.

\section{Ferrovia chegando...}

Segundo Flores (2007, p. 12), Santa Maria foi o mais importante centro ferroviário do Sul do Brasil na primeira metade do século XX. A ferrovia inicia suas atividades na cidade no ano de 1885 , trazendo traba- 
lhadores de várias nacionalidades: italianos, alemães, franceses, belgas, entre outros ${ }^{2}$. Com ela veio também novas formas de ver o mundo, de se vestir, de produzir e ainda de se relacionar com as noções de tempo e de espaço. Por meio de periódicos por nós analisados no projeto de pesquisa, observa-se o quanto a rotina da cidade dialogava com os horários e atividades da ferrovia, traçando com ela uma relação de dependência e troca.

Penso, como Lima (2003) ${ }^{3}$, ao enfatizar que havia uma cultura ferroviária pela qual eram transmitidos, de geração em geração, além de técnicas e saberes do mundo do trabalho, laços de solidariedade e de pertencimento. Segundo o autor, ser ferroviário representava estar vinculado não somente a empresa, mas especialmente aos "companheiros de trabalho" (LIMA, p. 54), a um espírito corporativo. Essa cultura, que pairava nas fronteiras entre o público e o privado, uma vez que era passada de pais para filhos em muitos casos, favorecia a visualização de uma grande família ferroviária. Como ressalta Harres (1996), havia a idealização de uma família ferroviária mais ampla e homogênea, na qual as estruturas hierárquicas tenderiam a ser invisibilizadas (HARRES, 1996). A ferrovia chegando trouxe essa nova forma de relacionar-se, em que o cooperativismo, mutualismo e a solidariedade de classe assumiram papel importante. Os ferroviários denominavam a rede ferroviária como "mãe carinhosa" (GARCIA, 2009, p. 18), para quem todos eram bem-vindos e assistidos. Contudo, como ressalta Segnini (1982), esse paternalismo no mundo do trabalho ferroviário poderia ser observado como instrumento de dominação também.
A cidade alastrou-se espacialmente acompanhando os trilhos. Bairros nasceram, clubes foram criados, hotéis e casas de serviço abertas e toda uma dinâmica urbana estabeleceu-se. Ao encerrar suas atividades no ano de 1996 deixou na cidade e em seus habitantes uma sensação de vazio (demográfico e econômico, entre outros), que está presente em algumas das narrativas que serão aqui analisadas.

\section{Tornar-se ferroviário, uma opção de vida}

Os ferroviários sentiam-se trabalhadores privilegiados e honrados, compartilhando um sentimento muito forte de coletivo e/ ou categoria. Havia uma preocupação em honrar a condição de trabalhador ferroviário e sua história ${ }^{4}$. Mas, quem eram os ferroviários? De onde provinham esses trabalhadores? Como se formavam? No interior do mundo do trabalho ferroviário havia vários segmentos, tais como o "pessoal de tráfego" e o "pessoal de tração" (termos a mim passados por ferroviários). No interior dessa divisão havia as várias ocupações específicas, de engenheiros especializados aos tucos (cuidadores e reparadores das linhas), como eram chamados os trabalhadores braçais mais desqualificados. Encontramos nas narrativas a distinção de "pessoal de pátio" e "pessoal de escritório" também, mas sempre se referindo às atividades mais ligadas aos trens em si e outras mais distantes destes. Tratava-se, também, em nossa compreensão, de proximidade à rotina dos trilhos e suas especificidades e movimentações. Foi criada no ano de 1922 a Escola de Artes e Ofícios, tida como uma instituição prepara- 
tória para o mundo do trabalho ferroviário na cidade. Essa escola preparou gerações de ferroviários e era reconhecida como de excelente qualidade e performance. Seus mestres e professores são lembrados até hoje pela comunidade santa-mariense.

Havia entre os trabalhadores ferroviários, homens brancos e negros e oriundos de nacionalidades diferenciadas. Por meio de pesquisa no acervo da Cooperativa dos Ferroviários de Santa Maria, pode-se constar a diversidade de procedências destes trabalhadores. Contudo, como aparecem estes nas narrativas? Observa-se que eram englobados pela categoria genérica de ferroviários. Como aponta Jobim (2008), apesar da aparente unidade de interesses e valores, havia divergências religiosas e também étnico-raciais no coletivo ferroviário ${ }^{5}$. Ressalta-se que a presença feminina era pouca, exercendo as mulheres atividades nos escritórios e outras rotinas consideradas mais leves (SILVA, 2010). Salienta-se, contudo que "mulher de ferroviário" era uma posição social de grande valor e muitas moças a almejavam. Eram muito comuns, também, os casamentos entre filhos de ferroviários. Algumas esposas de ferroviários faziam doces e outros lanches para venderem nas proximidades da estação, o que garantia uma renda extra à família.

Um longo poema escrito por Alexandre da Cruz (2004, p. 52-84), ferroviário aposentado, ilustra bem como se traduzia o processo de tornar-se ferroviário para um jovem rapaz com poucos recursos:

....eiteiro, vendedor de frutas ${ }^{6}$

Com 6 anos começou

Aos 14 anos na Viação Férrea

Um serviço arrumou

Trabalhando durante o dia

E à noite estudou
Como aprendiz foi admitido Como aprendiz de ajustador Até os dezoito nesta profissão Foi defender a Nação Senhor Era atleta do Riograndense Jogava como amador...

...Nas oficinas trabalhava

À tardinha ia treinar

Ganhava uns trocados

Que o ajudava a se arrumar

Defendendo várias equipes

Nos dias que ia jogar...

...Ferroviário sempre foi judiado

E tinha grande competência

O serviço que se fazia

Era duro e de muita ciência

Só que ninguém nos dava valor

Uns ignorantes sem consciência...

...Aprendi a trabalhar com muito capricho

Serviço bem feito e ligeiro

Por isso muito sofri

Com os chefes e companheiros

Executava minhas tarefas

Terminando sempre em primeiro...

...Trabalhei nas oficinas de máquinas

Depois no km 3 em vagão

Comecei arrumando relógio

Passei para a vedação

Trabalhando em manômetros

Velocímetros e transmissão.

Fui ajustador e torneiro

Rodeiros e a freio a ar

No controle e qualidade

Esta sessão fui criar

Atendendo o Diretor Romualdo

Que veio me convidar.

Em 1975 encerrei a vida ferroviária

Pude me aposentar

Depois de 30 anos de lutas

Quando saí para descansar

Dando um abraço nos amigos

Que continuaram a lutar... 
O livro por ele escrito, denominado $A$ história da viação férrea em Santa Maria - memórias de um aposentado, editado em 2004, narra a trajetória de vida do aposentado, suas vivências fora e dentro do universo de trabalho ferroviário. Para um jovem pobre, a ferrovia apresentava-se como um destino bom, garantindo subsistência e alguma ascensão social. Contudo, como ele mesmo narra na obra, havia tensões e desencontros na rotina dos afazeres ferroviários que eram sanados pelo sentimento de classe e de unidade para ganhos conjuntos. Em sua obra são relatados o papel importante do sindicato, as lutas da categoria e como, aos poucos, a ferrovia ia perdendo seu poder e influência.

Como aponta Grunewaldt (2007), a rotina de trabalho da ferrovia também se modificou ao longo do tempo, sendo incorporadas a esta buscas por eficiência, controle e disciplina sobre o trabalho ${ }^{7}$. Além disso, com os avanços tecnológicos, algumas funções perdiam sua importância.

\section{Trilhos e trens nos tempos e espaços}

Os anos ferroviários da cidade, de 1885 a 1996 deixaram marcas e saudades em muitos. Pode-se dizer que a cidade de Santa Maria está, ainda hoje, marcada pela presença ferroviária de inúmeras formas, sejam concretas ou imaginadas. Cidades e trilhos mesclam-se, numa envergadura entre passado e presente, deixando na arquitetura, espaços e traçados de sua influência (FOLETTO, 2008).

A cidade no passado, com sua gare, seu footing, os cafés, permitia aos cidadãos terem uma sociabilidade mais acentuada, pois esse espaço não era somente físico, mas sim de convívio e interações sociais também. Como narra Alexandre da Cruz (2004, p. 131):

“...A estação era um lugar de passeio

As jovens e os santa-marienses

A gare vivia cheia

Da juventude carente

Aqui nunca teve lazer

Passeava na gare e vivia contente..."

Ou seja, o espaço ferroviário era democrático em certo sentido, permitindo a todos circularem em seu entorno. $\mathrm{O}$ que não implica, contudo, que não houvesse distinções e clivagens entre os transeuntes. Pelas fotos analisadas da época, era comum homens e mulheres trajarem-se bem vistosos para o footing na gare. Outro aspecto que foi citado em várias entrevistas com ferroviários foi acerca da possibilidade de trânsito e de passeios que a ferrovia possibilitava a suas famílias:

O trem que ia de Santa Maria, ou vinha de Porto Alegre era luxuoso para a época. $\mathrm{Na}$ primeira classe, as poltronas eram de couro com um forro de linho na altura da cabeça, para o recosto e o sono que sempre vinha. Um vagão restaurante, acarpetado, toalhas de linho, cadeiras estofadas, garçons impecáveis na túnica branca, serviam os melhores bifes do estado. Claro que uma cervejinha gelada também vinha muito bem (PORTO, 1995, p. 123-124).

Segundo alguns ex-ferroviários entrevistados para a pesquisa, o preço atual das passagens rodoviárias inviabiliza as visitas familiares como havia antes. Famílias inteiras partiam em férias para casa de parentes em outras cidades isentas de pagamento de passagem, o que facilitava viagens mais constantes. Era o denominado "passe livre", que está presente na memória de muitos descendentes de ferroviários. Nesses pas- 
seios, de família inteira, foram-me relatados os preparativos, os lanches, as responsabilidades de cada membro familiar, permitindo a todos uma sociabilidade mais ampliada e uma vivência familiar mais constante. Conforme Alexandre da Cruz, em seus versos (2004, p. 132):
“...Trem não mais existe
O transporte disparou
As famílias não se visitam
O preço das passagens aumentou
Ninguém mais consegue
O dinheiro evaporou..."

Os jogos de futebol entre os times ferroviários também eram possibilitados pelo transporte que a ferrovia patrocinava a seus jogadores, levando e trazendo times para os torneios e as partidas. $\mathrm{Na}$ apresentação da obra Riograndense Futebol Clube (FLORES, 2012), os autores elaboram a seguinte narrativa sobre a presença ferroviária na cidade de Santa Maria:

Este livro é o nosso reconhecimento público aos trabalhadores ferroviários gaúchos, os grandes construtores da pujança do Rio Grande do Sul no século XX. Eles que, além do labor na Viação Férrea do Rio Grande do Sul, tiveram a ousadia para a organização mutual e cooperativista, nunca se esquecendo da educação, do lazer e das práticas desportivas. Literalmente, no futebol, "vestiram a camiseta" e honravam suas agremiações, dentre elas o Riograndense Futebol Clube, de Santa Maria. Bons tempos" (FLORES, 2012, apresentação).

Ou seja, há um reconhecimento coletivo na cidade a respeito da importância dos ferroviários e de seu trabalho. Há, igualmente, uma valorização "aos tempos da ferrovia", como construção positivada do passado. Contudo, o importante é chamar a atenção para o fato de que, apesar do fechamento da ferrovia, há uma invocação pública constante desta, seja por sua presença ou ausência. Ela é uma força evocativa continuada, tendo sido vivida de fato pelos evocadores ou por meio das memórias compartilhadas e das narrativas locais dos "tempos de ouro" da ferrovia.

\section{Considerações finais}

A história da cidade de Santa Maria e a história da rede ferroviária local estão intimamente interligadas e de uma forma que, por vezes, rever o passado da cidade significa rever o passado da história da ferrovia. Mais do que mundo do trabalho, a ferrovia e os ferroviários fizeram parte de um estilo de vida e de sentir santa-mariense, marcados por características concebidas como modernas e progressistas. Mundo privado e mundo doméstico, muitas vezes, se cruzavam possibilitando a vivência de um sentimento de familismo do mundo trabalho.

Nas narrativas aqui apresentadas, o que se evidencia é a força evocativa do mundo ferroviário e suas dinâmicas, gentes e especificidades. Tendo vivido "por tabela" ou de fato os acontecimentos que envolviam os trens, seus trilhos, apitos e reminiscências, importa ao pesquisador compreender a força desse elemento e o quanto marcou a vida das pessoas da cidade. Lugar de encontros e desencontros, a ferrovia permanece repleta de sentidos e sentimentos, favorecendo a constante revitalização de sua presença, mesmo que fisicamente o que se veja esteja em sucatas, como ressaltam os ferroviários. 


\section{Abstract}

This article aims to reflect on the process of constructing narratives related to the railway in the town of Santa Maria, located in the central region of the state of Rio Grande do Sul (Brazil). Through ethnographic and documentary research we objective in this article to the analyze narratives in which the railroad and its dynamics appear as force of expression. What is observed is that evocative power of presence and history of the railroad became a trademark of the city and its trajectory.

Keywords: Memories. Railway. Santa Maria.

\section{Resumen}

Este artículo tiene por objetivo reflejar sobre el proceso de construcción de narrativas memorialistas relativas al mundo ferrocarril en la ciudad de Santa Maria, situada en la región central del estado de Rio Grande do Sul (Brasil). Por medio de investigación documental y etnográfica, se hace en este artículo la analice de narrativas en las cuales el ferrocarril y sus distancias aparecen como motores de expresión. Lo que se observa es que el poder evocador de la presencia y de la historia del ferrocarril se tornaran una marca de la ciudad y de su trayectoria.

Palabras-clave: Memorias. Ferrocarril. Santa Maria.

\section{Notas}

1 Os dados aqui apresentados são resultados parciais dos projetos financiados pelo CNPq/FAPERGS/FIPE denominado Ferroviários em cena: trabalho, etnicidade e memórias operárias em Santa Maria-RS e A ferrovia, a cidade e mundo do trabalho ferroviário (seus saberes e fazeres): dinâmicas passadas e presentes em Santa Maria-RS. Sou grata pelo auxílio das estudantes de iniciação científica Juliana Franchi da Silva, Tricia Cardoso, Natana Botenzi, Rubia Machado, Jamile Costa e Silvana Silva de Oliveira.

2 Esse movimento populacional pode ser observado noutras regiões do estado também. Segundo Moura (2007, p. 54): “Com o tráfego regular à cidade de Santa Maria, em 1906 e com a conclusão das estações de Carazinho, em 1898, Passo Fundo, em 1900 e Ijuí, em 1912, o fluxo migratório atingiu elevados índices na região, elevando o índice populacional de algumas cidades como Cruz Alta e Passo Fundo à significativa monta".

3 Para Lima, "...os ferroviários podem ser considerados não somente como uma categoria profissional, mas como uma cultura, construída a partir de experiências comuns transformadas ao longo de gerações em uma tradição, fator central na construção de sua identidade" (LIMA, 2003, p. 52).

4 Como ressalta Grunewaldt (2007, p. 405), as chefias eram exercidas por homens casados, pois estes eram "tidos como mais responsáveis". Ou seja, o mundo do trabalho e o mundo da intimidade se cruzavam.

5 Jobim (2008) apresenta a trajetória de Charão, operário ferroviário negro e espírita que teve importante papel na greve de 1936.

6 Apresento aqui somente alguns trechos do poema.

7 Segundo a autora, esse controle "era feito por meio de chefias, ordens ou circulares (como a de 1924, que dispunha sobre as ferramentas: fornecimento, devolução dos artigos e extravios) e relatórios diários, mensais e anuais do tráfego, das oficinas e dos escritórios. Nos trens, havia livros de bordo" (2007, p. 398). 


\section{Bibliografia}

AUGÉ, Marc. Não-lugares. 5. ed. Campinas, SP: Papirus, 1994.

BELTRÃO, Romeu. Cronologia histórica de Santa Maria e do extinto município de São Martinho 1787-1930. 2. ed. S. L. 1979.

CRUZ, Alexandre da. A história da fiação férrea em Santa Maria. Memórias de um aposentado. Santa Maria: Palotti, 2004.

FLORES, João Rodolpho Amaral. Fragmentos da história ferroviária brasileira. Santa Maria: Palotti, 2007. (Estudos Ferroviários 1).

. Os trabalhadores da V.F.R.G.S. Santa Maria: Palotti, 2008. (Estudos Ferroviários 2).

FLORES, João Rodolpho Amaral (Org.). Riograndense futebol clube. Santa Maria: NEP/ UFSM, CCSH, Riograndense Futebol Clube, 2012.

FOLETTO, Vani Terezinha (Org.) et al. Apontamentos sobre a história da arquitetura de Santa Maria. Santa Maria: Palotti, 2008.

GARCIA, Eliana Rosa. Pelos trilhos: histórias da Vila Ferroviária de Porto Alegre. Porto Alegre: Secretaria Municipal de Cultura, 2009.

GRUNEWALDT, Silvana. A reforma de 1942 na VFRGS e o estabelecimento de uma nova cultura do trabalho. IV Jornada do GT Mundos do Trabalho-RS. Pelotas, 08 a 11 de outubro de 2007. Disponível em: <www.ufpel.tche.br/ ich/ndh/.../resumos/Silvana_Grunewaldt. pdf>. Acesso: jul. 2010.

HALBWACHS, Maurice. A memória coletiva. São Paulo: Vértice, Editora Revista dos Tribunais, 1990.

HARDMAN, Francisco Foot. Trem fantasma. A modernidade na selva. São Paulo: Cia das Letras, 1988.

HARRES, Marluza Marques. Disciplina e trabalho: administração de iniciativa na VFGRS.
Estudos ibero-americanos. Porto Alegre, v. XXII, n. 2, p. 111-127, 1996.

HILLIG, Silvana G. Entre trilhos e sobre rodas: racionalização, disciplina e resistência no sistema férreo do Rio Grande do Sul (1920-1949). Tese de doutorado. PUC/SP, 2000.

LIMA, Rogério Mendes de. Uma categoria fora dos trilhos: reflexões sobre a crise de identidade entre os ferroviários do Rio de Janeiro. In: SANTOS, José Vicente Tavares dos (Org.) et al. Transformações no trabalho no século XXI. Pelotas: Educat, 2003. p. 49-77.

MACEDO, João Heitor Silva. O negro e a ferrovia no interior do Rio Grande do Sul: a Sociedade Treze de Maio como fator de identidade da cultura negra em Santa Maria no início do século XX. In: QUEVEDO, Júlio; DUTRA, Maria Rita Py. Nas trilhas da negritude. Porto Alegre: Martins Livreiro, 2007. p. 87-98

POLLAK, Michael. Memória, esquecimento, silêncio. Estudos Históricos, Rio de Janeiro, v. 2, n. 3, p. 3-15, 1989.

Memória e identidade social. Estudos Históricos, Rio de Janeiro, v. 5, n. 10, p. 200-212, 1992.

PORTO, João Teixeira. A linha férrea. In: Antologia em prosa e verso. Associação Santa-mariense de Letras: Palotti, 1995. p. 121-124.

SILVA, Juliana Franchi da. As mulheres por trás dos trilhos. Artigo de graduação. Santa Maria, 2010. Curso de Ciências Sociais/IFSM. Disponível em: <www.ufsm.br/csociais>.

SOUZA, Robério Santos. Experiências de trabalhadores nos caminhos de ferro da Bahia: trabalho, solidariedade e conflitos (1892-1909). Dissertação de Mestrado. Departamento de História. UNICAMP, 2007.

VIANA, Vilma. O ventre da Maria-fumaça. Corag: Porto Alegre, 2006. 